\title{
Digestive System Stenosis
}

National Cancer Institute

\section{Source}

National Cancer Institute. Digestive System Stenosis. NCI Thesaurus. Code C79468.

A narrowing or stricture within the digestive system. 